\title{
Brief alcohol intervention and health-related quality of life among primary health care patients in Estonia
}

\author{
KAJA PÕLLUSTEE ${ }^{1, A, C-F}$, MARGUS LEMBER ${ }^{1,2, A, D-G}$ \\ ${ }^{1}$ Institute of Clinical Medicine, University of Tartu, Estonia \\ ${ }^{2}$ Tartu University Hospital, Internal Medicine Clinic, Estonia
}

A - Study Design, B - Data Collection, C - Statistical Analysis, D - Data Interpretation, E - Manuscript Preparation, F - Literature Search, G - Funds Collection

Summary Background. The effectiveness of brief interventions (BI) in reducing hazardous or harmful drinking among primary health care (PHC) patients has been confirmed by a number of studies; however, there is a lack of evidence regarding the effect of $\mathrm{BI}$ on health-related quality of life (HRQoL).

Objectives. This study aimed to find out whether the changes in alcohol consumption (AC) are associated with changes in HRQoL scores among PHC patients with hazardous and harmful drinking habits.

Material and methods. 93 adult PHC patients with an alcohol disorder underwent BI, with the outcomes assessed after a follow-up period of 12 months. The main outcomes measures were the Alcohol Use Disorders Identification Test (AUDIT) score and physical (PCS) and mental (MCS) component scores of HRQoL (using SF-36). Linear regression analysis was used to explain the follow-up value of PCS and MCS in association with the change of the AUDIT score during the follow-up period.

Results. 12 months post-BI, $82 \%$ of the study participants had a significantly lower average AUDIT score (from $12.3 \pm 0.5$ to $7.5 \pm 0.5$, $p<0.001)$ and higher HRQoL PCS $(68.3 \pm 2.5$ to $76.1 \pm 2.0, p<0.05)$. The regression analysis showed that the decrease of AUDIT scores during the follow-up period was positively associated with PCS in patients aged 18-44 but did not have a significant effect in patients aged 45 and older. The MCS was not associated with a decrease in the AUDIT score.

Conclusions. A reduced AUDIT score post-BI leads to improved physical HRQoL for younger PHC patients with formerly hazardous and harmful drinking habits.

Key words: alcohol drinking, Alcohol Use Disorders Identification Test (AUDIT), intervention studies, quality of life, 36-Item Short Form Health Survey (SF-36), follow-up studies.

Põlluste K, Lember M. Brief alcohol intervention and health-related quality of life among primary health care patients in Estonia. Fam Med Prim Care Rev 2018; 20(2): 154-158, doi: https://doi.org/10.5114/fmpcr.2018.73848.

\section{Background}

The effectiveness of brief intervention (BI) for problem alcohol consumption (AC) has been an object of research since the late 1980s [1]. A widely used instrument for the screening of alcohol misuse is the Alcohol Use Disorders Identification Test (AUDIT), which was developed in 1993 by World Health Organization (WHO) experts [2]. The AUDIT consists of 10 questions. The first three questions evaluate drinking quantity and frequency. The remaining questions proceed to evaluate symptoms of alcohol dependence (questions 4-6) and harmful drinking (questions 7-10). All 10 questions are scored from 0 to 4 , with a maximum score of 40 . The original cut-off for risky drinking was 8 or more points [2], which has been accepted as a cut-off value to identify hazardous and harmful drinking in the Estonian primary health care (PHC) system as well [3]. The validity and diagnostic usefulness of the AUDIT has been confirmed in several studies [4-6]. When an individual has a screening result referring to an alcohol use disorder, WHO experts suggested providing a $\mathrm{BI}$, the recommended content and length of which depends on the AUDIT score of the patient [2]. A number of studies have confirmed the effectiveness of $\mathrm{BI}$ at reducing hazardous or harmful drinking in PHC settings $[7,8]$. In Estonia, the high level of alcohol consumption has been a significant public health problem for many years. Since the late 2000s and early 2010s, interventions on a personal level for early identification and counselling of alcohol-related health problems were launched in PHC, in addition to other measures applied on the population level (e.g. legislative restrictions on sales, commercials, public awareness campaigns, etc.) [9]. In 2010, the first pilot study to evaluate the methods for early identification of risk drinking and counselling in the PHC system in Estonia was conducted. The results of this study demonstrated that $23 \%$ of patients aged 18-64 had hazardous or harmful drinking habits, whereby the level of risk drinking was highest among patients aged 18-44 [3]. On the other hand, the authors of this study concluded that completing the AUDIT questionnaire was easy for most patients and that early identification of risk drinking and counselling is feasible [3].

Harmful AC significantly contributes to the burden of chronic diseases and conditions [10] and is implicated in reduced health-related quality of life (HRQoL) [11-13], irrespective of a person's gender or health status [14]. Thus, reduced AC is expected to lead to improved health; however, the evidence for health-related outcomes with reference to behavioral counselling interventions remains insufficient [15]. Recent evidence suggests that treatment interventions and abstinence help to improve the HRQoL of patients with a history of alcohol abuse and dependence $[13,16,17]$; however, far too little attention has been paid to the effect of $\mathrm{BI}$ in PHC settings on the HRQoL of patients with hazardous or harmful drinking habits.

\section{Objectives}

Among the numerous papers reporting the effectiveness of $\mathrm{BI}$ at reducing the hazardous and harmful drinking of PHC pa- 
tients, we found no studies that focused on HRQoL as an outcome measure of $\mathrm{BI}$. In this paper, we report on a study that concurrently investigated changes in the AUDIT score and self-reported HRQoL before and after a BI in Estonian PHC settings among patients with a history of hazardous and harmful drinking habits. This study aimed to find out whether there is an association between the changes in AUDIT and HRQoL scores of $\mathrm{PHC}$ patients with hazardous and harmful drinking habits.

\section{Material and methods}

\section{Study design and setting}

Data for this follow-up study was collected in six Estonian PHC centers from May 2013 to December 2014. The centers were selected according to the following criteria:

1) they were representative of different Estonian regions, e.g. urban and rural, Estonian and Russian speaking;

2) the family doctor (FD) or practice nurse had completed the relevant $\mathrm{BI}$ training.

\section{Sampling and participants}

Initially, 840 consecutive patients aged $18-92$ years (mean value 47.8 years) were recruited, of them $38 \%$ were male patients. Compared to the total population in Estonia in 2013, in the study sample, the proportion of men was lower (38\% vs $46 \%)$, and the proportion of persons aged 45 and more was slightly higher ( $58 \%$ vs $55 \%$ ). Patient participation was voluntary. All patients were informed about the objectives of the study, and those willing to participate signed an informed consent form. Only adult patients (aged $\geq 18$ ) were recruited. Of these 840,133 screened positive for an alcohol use disorder and were included in the follow-up study. The mean age of the patients in the follow-up group was 38.1 years (range from 18 to 75 years), $79 \%$ were males.

\section{Data sources and variables}

The study protocol included self-reported data and data recorded by an FD or practice nurse. All data was collected at baseline and a follow-up point at 12 months. Each patient completed the self-administered questionnaire, including the AUDIT and 36-Item Short Form Health (SF-36). According to their AUDIT score, patients were categorized into four groups: low-risk drinking (score 0-7); hazardous drinking habits (score: 8-15); harmful drinking habits (16-19); possible alcohol dependence $(\geq 20)$ [2]. Information about existing chronic conditions was collected from patient health records.

The patients' HRQoL was measured using the SF-36, which is a valid and reliable generic measure for comparing general and specific population groups [18]. This instrument contains 36 questions covering functional health status and general health, both currently and over the previous four weeks. The questions are summarized into eight scales measuring physical functioning, role physical, bodily pain, general health perception, vitality, social functioning, role emotional, and emotional wellbeing. Physical and mental component summary scores (PCS and MCS, respectively) can be calculated on the basis of these subscales. The scale scores range from 0 to 100 , with higher scores indicating a better health status.

\section{Intervention and outcome measure}

All patients with an AUDIT score $\geq 8$ were delivered the appropriate $\mathrm{BI}$ according to their score immediately after the screening process. Based on WHO recommendations [2], patients with a score from 8-15 were given simple advice, and patient education materials focused on the reduction of hazardous drinking. Harmful drinkers (score of 16-19) received simple advice and brief counselling. Patients with possible alcohol dependence (score of $\geq 20$ ) were recommended to visit a psychiatrist. The outcome measures were patients' self-reported drinking status (as measured by AUDIT) and HRQoL (as measured by SF-36) after a follow-up period of 12 months.

\section{Statistical analysis}

We used the $\chi^{2}$-test and ANOVA to compare the baseline and follow-up measures and to discover any possible differences between those who did and did not participate in the follow-up study. A Pearson correlation coefficient was used to describe the relationship between the continuous variables, such as age and HRQoL scores; linear regression analysis was used to discover the associations between the changes in AUDIT and HRQoL scores after the 12-month follow-up. The preliminary analysis of data showed a significant difference in baseline as well in the follow-up PCS of HRQoL scores between patients aged 18-44 and 45+, but no difference in baseline or follow-up AUDIT scores regarding the age groups. Thus, the association between the AUDIT and HRQoL scores were analyzed in both age groups. In total, four models were calculated - two of them exploring changes in PCS and MCS as dependent variables in the younger age group - and adjusted for the baseline AUDIT, PCS, and MCS scores, as well age. The remaining two models describe the same association with reference to older patients. A significance level was set at $p<0.05$. Statistical analysis was performed using SPSS for Windows (version 23.0; SPSS Inc., Chicago, IL, USA).

\section{Ethical approval}

The study design was approved by the Ethics Review Committee on Human Research of the University of Tartu (Protocol No. 223/T-16 on 25 February 2013).

\section{Results}

Of the 133 patients who screened positive for an alcohol use disorder, 93 (69.9\%) attended the follow-up visit after 12 months. The main reasons of drop-out were leaving abroad to work, change of FD, or loss of health insurance during the year; 12 patients refused to participate in the follow-up study. Patients who participated in the follow-up visit were significantly older $(p<0.01)$, less likely to be a smoker $(p<0.05)$, and more likely to have at least one chronic illness $(p<0.05)$. No significant differences occurred between the groups regarding gender, AUDIT scores, and PCS and MCS. The characteristics of the follow-up and drop-out groups are presented in Table 1.

During the 12-month follow-up period, the mean AUDIT score of the whole study group decreased from $11.9 \pm 0.4$ to 8.6 \pm 0.5 ( $p<0.001)$. Of the 93 follow-up participants, 76 (81.7\%) reported a significantly decreased AUDIT score compared to the pre-BI mean ( \pm SD) $(12.3 \pm 4.3$ and $7.5 \pm 4.4$, respectively, $p<$ $0.001) .17$ patients reported an increase $(n=16)$ or no change $(n=1)$ in their AC; the mean AUDIT score in this group increased $10.4 \pm 2.5$ to $13.2 \pm 5.6, p=0.065$. There were no significant differences between these two groups in terms of age, gender, or baseline HRQoL. The 76 patients with decreased AUDIT scores exhibited a significant increase in the mean $( \pm$ SD) PCS (68.3 \pm 20.9 to $76.1 \pm 17.4, p<0.05)$. MCS also increased; however, this difference was not statistically significant $(68.2 \pm 20.8$ to $73.9 \pm$ $16.7, p=0.068$ ). Three of the 76 patients who reported reduced $A C$ at follow-up claimed to have ceased smoking, and a further three had reduced their BMI from overweight to normal (BMI of $<25)$. Patients with an increased AUDIT score had lower post-BI HRQoL PCS (71.4 \pm 22.0 to $69.2 \pm 26.6, p=0.218)$ and MCS $(69.7$ \pm 21.7 to $67.2 \pm 22.3, p=0.738$ ), but the differences between mean baseline and follow-up scores were not statistically different. There were no significant differences between mean base- 


\begin{tabular}{|c|c|c|}
\hline & $\begin{array}{l}\text { Follow-up group } \\
(n=93)\end{array}$ & $\begin{array}{l}\text { Drop-out group } \\
(n=40)\end{array}$ \\
\hline $\begin{array}{l}\text { Age group }(\%), p<0.01 \\
18-44 \\
45 \text { and older }\end{array}$ & $\begin{array}{l}63.4 \\
36.6\end{array}$ & $\begin{array}{l}95.0 \\
5.0\end{array}$ \\
\hline $\begin{array}{l}\text { Gender }(\%), p=0.814 \\
\quad \text { Male } \\
\text { Female }\end{array}$ & $\begin{array}{l}80.6 \\
19.4\end{array}$ & $\begin{array}{l}77.5 \\
22.5\end{array}$ \\
\hline $\begin{array}{l}\text { Smoking status (\%), } p<0.05 \\
\text { Non-smoker } \\
\text { Smoker }\end{array}$ & \begin{tabular}{|l|}
53.3 \\
46.7 \\
\end{tabular} & $\begin{array}{l}32.5 \\
67.5 \\
\end{array}$ \\
\hline At least one known chronic disease (\%), $p<0.05$ & 66.7 & 43.6 \\
\hline $\begin{array}{l}\text { Alcohol consumption according to AUDIT score (\%), } p=0.733 \\
\text { Hazardous drinking (score of } 8-15 \text { ) } \\
\text { Harmful drinking (score of } 16-19 \text { ) } \\
\text { Possible dependence (score of } \geq 20 \text { ) }\end{array}$ & $\begin{array}{l}83.9 \\
9.7 \\
6.4 \\
\end{array}$ & \begin{tabular}{|l|l|}
82.5 \\
7.5 \\
10.0 \\
\end{tabular} \\
\hline Baseline AUDIT score (mean and SE), $p=0.596$ & $11.9 \pm 0.4$ & $12.4 \pm 0.7$ \\
\hline $\begin{array}{l}\text { Baseline SF-36 health-related quality of life (mean and SE) } \\
\text { Physical component score PCS, } p=0.721 \\
\text { Mental component score MCS, } p=0.530\end{array}$ & $\begin{array}{l}68.9 \pm 2.2 \\
68.5 \pm 2.2\end{array}$ & $\begin{array}{l}70.4 \pm 3.7 \\
65.7 \pm 3.8\end{array}$ \\
\hline
\end{tabular}

\begin{tabular}{|c|c|c|c|c|}
\hline \multicolumn{5}{|c|}{ Unstandardized coefficients B (95\% C.I.)* for the follow-up physical component score (PCS) } \\
\hline \multirow[t]{2}{*}{ Independent variables } & \multicolumn{2}{|c|}{ Patients aged $18-44$ years, adj $R^{2}=0.21$} & \multicolumn{2}{|c|}{ Patients aged 45 and over, adj $R^{2}=0.67$} \\
\hline & B (95\% C.I.) & $p$ & B (95\% C.I.) & $p$ \\
\hline Baseline PCS & $0.367(-0.163,0.572)$ & 0.001 & $0.789(0.559,1.018)$ & $<0.001$ \\
\hline Baseline AUDIT score & $-0.729(-1.624,1.660)$ & 0.108 & $0.961(-0.604,2.527)$ & 0.218 \\
\hline $\begin{array}{l}\text { Difference between baseline and } \\
\text { follow-up AUDIT scores }\end{array}$ & $0.819(0.007,1.631)$ & 0.048 & $0.582(-0.920,2.085)$ & 0.432 \\
\hline Age & $-0.083(-0.588,0.421)$ & 0.742 & $-0.501(-1.175,0.173)$ & 0.139 \\
\hline \multicolumn{5}{|c|}{ Unstandardized coefficients B (95\% C.I.)* for the mental component score (MCS) } \\
\hline \multirow[t]{2}{*}{ Independent variables } & \multicolumn{2}{|c|}{ Patients aged $18-44$ years, adj $R^{2}=0.27$} & \multicolumn{2}{|c|}{ Patients aged 45 and over, adj $R^{2}=0.38$} \\
\hline & B (95\% C.I.) & $\mathrm{p}$ & B (95\% C.I.) & $\mathrm{p}$ \\
\hline Baseline MCS & $0.463(0.262,0.664)$ & $<0.001$ & $0.590(0.313,0.687)$ & $<0.001$ \\
\hline Baseline AUDIT score & $0.590(-1.573,0.394)$ & 0.234 & $0.845(-0.908,2.597)$ & 0.330 \\
\hline $\begin{array}{l}\text { Difference between baseline and } \\
\text { follow-up AUDIT scores }\end{array}$ & $0.637(-0.017,1.891)$ & 0.054 & $0.914(-0.845,2.672)$ & 0.294 \\
\hline Age & $-0.131(-0.692,0.429)$ & 0.640 & $-0.231(-1.025,0.563)$ & 0.554 \\
\hline
\end{tabular}

* Significant coefficients $(p<0.05)$ are displayed in boldface type.

line and follow-up AUDIT scores and HRQoL PCS or MCS based on gender. A moderate negative correlation appeared between the age and PCS of HRQoL $(r=-0.41, p<0.0001)$, but no relationship between the age and MCS of HRQoL was found. The mean $( \pm$ SD) baseline PCS in patients aged 18-44 was $72.6 \pm 17.1$, and in patients 45 and older, it was $61.6 \pm 25.8(p<0.05)$. The mean follow-up PCSs were $80.1 \pm 14.5$ and $64.0 \pm 23.9$, respectively $(p<0.0001)$. Strong positive correlations were found between the baseline and follow-up values of PCS and MCS $(r=0.68$, $p<0.0001$ and $r=0.58, p<0.0001$ ).

Regression analysis (Table 2 ) indicated that, in general, the greater the reported reduction in AC (based on pre- and post-BI AUDIT scores), the greater the increase in reported PCS at follow-up, irrespective of a patient's baseline AUDIT and PCS scores or age. Still, this association was valid only in the younger age group, i.e. in patients aged $18-44$ years. In patients aged 45 and older, the strongest predictor of the follow-up PCS was their baseline PCS. Decreased AUDIT scores did not have a significant association with MCS, neither in younger nor older patients; only a strong association between the baseline and follow-up MCS was found.

\section{Discussion}

\section{Key results and interpretation}

In our study, we confirmed the effectiveness of $\mathrm{BI}$ in reducing $A C$, but we also found that the greater self-reported decrease in $\mathrm{AC}$ between the $\mathrm{BI}$ and the follow-up at 12 months was associated with increased PCS, regardless of a patient's age or baseline AUDIT and PCS scores. However, this association presented only among the younger patients. The results of a previous study suggested that older age combined with hazardous or harmful drinking had a negative association with PCS [14]. Thus, it is possible that among the middle-aged and older patients, the lower PCS is a reflection of the consequences of prolonged hazardous or harmful drinking, and for that reason, the positive effect of decreased AC on the PCS is less expressed 
than in younger people. Still, this hypothesis could not be tested in this study, as the AUDIT questionnaire provides only for the screening of alcohol misuse but does not explain the prolonged history of AC.

Previously, improvement of HRQoL in association with reduced AC has only been described in studies that involved patients with alcohol dependence where the reduction or cessation of alcohol consumption or treatment interventions improved the mental and physical wellbeing of the patients [13, $16,17]$. The results of the present study indicate that it is likely that reduced AC among patients with a history of hazardous or harmful drinking may have the same positive effect on PCS of HRQoL as treatment for patients with alcohol dependence. Therefore, improvement of HRQoL following a reduced AUDIT score highlights the importance of alcohol misuse screening and $\mathrm{BI}$. It must be stressed that the association between a decreased AUDIT score and increased PCS became obvious among patients aged $18-44$ who are considered to be at high risk of alcohol misuse [19]. Therefore, identification and counselling of hazardous and harmful drinkers among the younger adults and patients in the younger middle-age group might be the most effective way to prevent alcohol-related harm in older age. Our findings might encourage FDs to extend alcohol misuse screening and relevant interventions to the majority of their patients, since according to recent evidence, the detection of risky $A C$ and other lifestyle risk factors does not always occur [20]. Taking into consideration the Estonian PHC system, the implementation of $A C$ screening and $B I$ in routine practice seems to be promising: within the alcohol prevention program initiated and implemented by the National Institute of Health Development in 2014 [21], a number of FDs and practice nurses have already been trained in early detection of hazardous and harmful AC and $\mathrm{BI}$, and step-by-step, these services are implemented in $\mathrm{PHC}$ practices as well.

\section{Limitation and generalizability of results}

A limitation exists, howerver, related to the study design. In this before-after study, we did not have a control group; thus, the possible confounders were not controlled, and causality cannot be demonstrated. Additionally, the unexpected loss of 40 patients during the follow-up led to another limitation - the rather small number of study subjects restricted any additional possible analysis, e.g. to discover the associations between reduced $A C$ and $H R Q O L$ with regard to gender, or to discover whether there is an association between the reduced $A C$ and MCS of HRQoL, as was demonstrated in some previous studies [11-14]. Thus, to find out the causal relationship between the $\mathrm{BI}$ and HRQoL among PHC patients with hazardous or harmful drinking habits, more studies with larger samples are needed.

\section{Conclusions}

Our results demonstrated that a reduced AUDIT score leads to improved HRQoL in terms of physical health for younger PHC patients with a history of hazardous or harmful drinking. Thus, screening for $\mathrm{AC}$ and $\mathrm{BI}$ are relevant preventive measures which could be strongly recommended to apply at the PHC level.

Source of funding: This work was supported by the European Regional Development Fund through the Estonian Research Council's health research promotion program TerVE (grant number 3.2.1002.11-0002) and the Institutional research grant IUT 2-8.

Conflict of interest: The authors declare no conflict of interests.

\section{References}

1. McCambridge J, Cunningham JA. The early history of ideas on brief interventions for alcohol. Addiction 2014; 109(4): 538-546.

2. Babor T, Higgins-Biddle JC, Saunders J, et al. AUDIT - The Alcohol Use Disorders Identification Test: guidelines for use in primary care. 2nd ed. Geneva: World Health Organization; 2001.

3. Saame I, Gluškova N, Viilmann K, et al. Prooviuuring alkoholi liigtarvitamise varajase avastamise ja nõustamise metoodika hindamiseks Eesti perearstisüsteemis. Eesti Arst 2011; 90(5): 216-224 (in Estonian).

4. Gache P, Michaud P, Landry U, et al. The Alcohol Use Disorders Identification Test (AUDIT) as a screening tool for excessive drinking in primary care: reliability and validity of a French version. Alcohol Clin Exp Res 2005; 29(11): 2001-2007.

5. Reinert DF, Allen JP. The alcohol use disorders identification test: an update of research findings. Alcohol Clin Exp Res 2007; 31(2): 185-199.

6. de Torres LA, Rebollo EM, Ruiz-Moral R, et al. Diagnostic usefulness of the Alcohol Use Disorders Identification Test (AUDIT) questionnaire for the detection of hazardous drinking and dependence on alcohol among Spanish patients. Eur J Gen Pract 2009; 15(1): 15-21.

7. Kaner EF, Beyer F, Dickinson HO, et al. Effectiveness of brief alcohol interventions in primary care populations. Cochrane Database Syst Rev 2007 Apr 18; (2): CD004148.

8. O'Donnell A, Anderson P, Newbury-Birch D, et al. The impact of brief alcohol interventions in primary healthcare: a systematic review of reviews. Alcohol Alcohol 2014; 49(1): 66-78.

9. Lai T, Habicht J. Decline in alcohol consumption in Estonia: combined effects of strengthened alcohol policy and economic downturn. Alcohol Alcohol 2011; 46(2): 200-203.

10. Shield KD, Parry C, Rehm J. Chronic diseases and conditions related to alcohol use. Alcohol Res 2013; 35(2): 155-173.

11. Mathiesen EF, Nome $\mathrm{S}$, Eisemann $\mathrm{M}$, et al. Drinking patterns, psychological distress and quality of life in a Norwegian general population-based sample. Qual Life Res 2012; 21(9): 1527-1536.

12. Dissing AS, Gil A, Keenan K, et al. Alcohol consumption and self-reported (SF12) physical and mental health among working-aged men in a typical Russian city: a cross-sectional study. Addiction 2013; 108(11): 1905-1914.

13. Levola J, Aalto M, Holopainen A, et al. Health-related quality of life in alcohol dependence: a systematic literature review with a specific focus on the role of depression and other psychopathology. Nord J Psychiatry 2014; 68(6): 369-384.

14. Põlluste K, Aart A, Kallikorm R, et al. Adverse lifestyle and health-related quality of life: gender differences in patients with and without chronic conditions. Scand J Public Health 2016; 44(2): 209-216.

15. Jonas D, Garbutt J, Brown J, et al. Screening, behavioral counseling, and referral in primary care to reduce alcohol misuse. Rockville, MD: Agency for Healthcare Research and Quality; 2012.

16. Ugochukwu C, Bagot KS, Delaloye S, et al. The importance of quality of life in patients with alcohol abuse and dependence. Harv Rev Psychiatry 2013; 21(1): 1-17, doi: 10.1097/HRP.0b013e31827fd8aa.

17. Daeppen JB, Faouzi M, Sanchez N, et al. Quality of life depends on the drinking pattern in alcohol-dependent patients. Alcohol Alcohol 2014; 49(4): 457-465.

18. Ware Jr JE. SF-36 Health Survey Update. SPINE 2000; 25(24): 3130-3139.

19. Anderson P, Gual A, Colom J. Alcohol and primary health care. Clinical guidelines on identification and brief interventions. Barcelona: Department of Health of the Government of Catalonia; 2005. 
20. Bryant J, Yoong SL, Sanson-Fisher R, et al. Is identification of smoking, risky alcohol consumption and overweight and obesity by General Practitioner's improving? A comparison over time. Fam Pract 2015; 32(6): 664-671.

21. National Institute of Health Development: Kainem ja tervem Eesti [Soberer and healthier Estonia, in Estonian] (cited: 8.02.2018). Available from URL: http://www.tai.ee/et/kainem-ja-tervem-eesti.

Tables: 2

Figures: 0

References: 21

Received: 22.01.2018

Reviewed: 05.02.2018

Accepted: 12.02 .2018

Address for correspondence: Kaja Põlluste, MD, PhD

Institute of Clinical Medicine

University of Tartu

L. Puusepa 8

Tartu 51014

Estonia

Tel.: +3727318607

E-mail: kaja.polluste@ut.ee 